\title{
Analysis of the changes in the lacrimal system before and after endoscopic dacryocystorhinostomy
}

Sha Li

Wuhan Aier Eye Hospital https://orcid.org/0000-0001-5471-8059

Yijun Zheng

Wuhan Aier Eye Hospital

Yong Zhang ( $\square$ lissingoo@hotmail.com )

https://orcid.org/0000-0003-1402-9229

Lin Chen

Wuhan Aier Eye Hospital

Research article

Keywords:

Posted Date: June 2nd, 2020

DOI: https://doi.org/10.21203/rs.3.rs-30963/v1

License: @ (i) This work is licensed under a Creative Commons Attribution 4.0 International License. Read Full License 


\section{Abstract}

\section{Background}

We aimed to analys and explore the changes in the lacrimal system before and after endoscopic dacryocystorhinostomy (EN-DCR).

\section{Methods}

A series of case studies was reviewed. The clinical data of 104 patients (120 eyes) who underwent ENDCR in our hospital from March 2019 to October 2019 were selected for the study. The tear meniscus height (TMH) and the Schirmer I test (SIt) values were compared preoperatively and 1 month and 3 months postoperatively and statistically analysed by Mauchly's test of sphericity and the Pearson correlation coefficient.

\section{Results}

The TMH decreased across all 3 timepoints, and the differences were statistically significant $(P<0.05)$. The TMH values were measured 3 times in 120 eyes and showed three patterns: increased steadily (34 eyes), descended first and then ascended (32 eyes), and decreased steadily (54 eyes); the changes in the three patterns were statistically significant $(P<0.05)$. There were a significant increases in SIt values among the three timepoints, and the SIt values gradually increased when the SIt values were $<10 \mathrm{~mm} / 5$ min preoperatively. However, there was no significant difference in SIt values when the SIt values were $\geq$ $10 \mathrm{~mm} / 5 \mathrm{~min}$ preoperatively. The TMH was highly correlated with the SIt value preoperatively $(r=0.763)$, moderately correlated at 1 month postoperatively $(r=0.515)$, and not correlated at 3 months postoperatively $(r=0.097)$.

\section{Conclusions}

EN-DCR has a certain degree of influence on the tear system, which is not only reflected in the tear drainage system, but also in the tear secretion system and the interaction between the two systems; however, excess tear drainage, can also alleviate dry eyes.

\section{Funding programme}

Joint Fund Project of Hubei Provincial Health Select Committee (No. WJ2019H318); General Key Projects of Medical Research in Wuhan City, Hubei Province (No. WX19A03)

\section{Background}

Endoscopic dacryocystorhinostomy (EN-DCR) is a kind of operation in which the lacrimal sac is anastomosed with the nasal mucosal flap under direct vision from nasal endoscopy to establish a new lacrimal drainage channel [1]. Most of the patients complained of long-term overflow of tears or 
secretions, and the lacrimal duct reconstructed by EN-DCR could relieve the symptoms of overflow of tears and pus [2]. The tear system controls the delicate balance between tear production and excretion, which is constantly influenced by biological, environmental and physical factors $[3,4]$. When the structure of the lacrimal duct changes, the lacrimal secretion system also undergoes subtle changes. Some scholars have reported that there are significant changes in the tear-related indexes before and after lacrimal duct obstruction $[5,6]$. These changes are easily ignored by clinicians. In this study, 104 cases (120 eyes) of EN-DCR were selected to met the clinical cure standard. According to the tear meniscus height (TMH) and the Schirmer I test (SIt) values before and after the operation, the influence of EN-DCR on the tear system was analysed.

\section{Methods}

\section{General information}

A retrospective review of a series of case studies was conducted to collect the clinical data of 104 patients (120 eyes) who underwent EN-DCR in our hospital from March 2019 to October 2019. The mean age of the patients was $57.18 \pm 10.87$ years ( \pm standard deviation (SD)) with a range from 27 to 78 years. The surgical treatment of all patients was performed by the same skilled surgeon, and the patients provided informed consent and signed the informed consent form. The study was conducted following the tenets of the Helsinki Declaration and was approved by the medical ethics committee (approval No.: WHS2019052706).

\section{Inclusion criteria}

(1) The chief complaint was an occasional history of tears and/or pus preoperatively; (2) during the preoperative examination of lacrimal passage irrigation, it was suggested that the lacrimal duct flushed up and back, the needle could touch the bone wall, and the reflux fluid was with or without secretions; (3) one month postoperatively, the patient mentioned that there was no obvious symptom of an overflow of tears or pus, and the lacrimal passage irrigation examination showed that the lacrimal passage was unobstructed; and (4) (clinical cure standard) 3 months postoperatively: the patient mentioned that there was no obvious symptom of an overflow of tears or pus, lacrimal passage irrigation examination indicated that the lacrimal passage irrigation was unobstructed, endoscopy showed that the lacrimal duct anastomosis formed well, and no adhesions and no granulation hyperplasia were observed.

\section{Exclusion criteria}

(1) Complicated with diseases of the eyelid, eye surface, lacrimal spot or lacrimal canaliculus; (2) nasal polyps; (3) nasal tumour or previous radiotherapy and chemotherapy; (4) injuries to the nose or eyelids; (5) deviation of nasal septum; (6) hypertrophy of turbinate; (7) serious diseases such as those affecting

the blood system; (8) inability to tolerate the operation; (9) incomplete medical records; and (10) failure to reach the clinical cure standard 3 months postoperatively. One of the above 10 items was valid for exclusion. 


\section{Preoperative examination and postoperative management}

Nasal endoscopy, lacrimal passage irrigation, slit lamp microscopy and routine physical examination were performed, the TMH was measured by a Graph 4 anterior segment analysis system, the basal lacrimal secretion was measured by an Slt strip, and the length of filter paper wetting for 5 min was recorded [7].

EN- DCR was performed under nasal endoscopy. All patients were treated with levofloxacin eye drops for 3 months. One month and 3 months postoperatively, the lacrimal duct anastomosis and lacrimal passage irrigation were examined under nasal endoscopy. A Graph 4 anterior segment analysis system was used to measure the TMH and Sit measurements.

\section{Statistical analysis}

The SPSS 19.0 software package was used for statistical analysis. Descriptive statistics included the average value and range, the measurement data that followed a normal distribution are expressed as mean $\pm S D$, and the calculated counting data, $120 \mathrm{TMH}$ points and SIt values were analysed by Mauchly's test of sphericity. A $P$ value $<0.05$ was considered statistically significant. The correlation between $\mathrm{TMH}$ data and SIt values was tested and analysed by the Pearson correlation coefficient, and the correlation coefficient " $r$ " was calculated.

\section{Results}

The mean $\mathrm{TMH}$ in 120 eyes was $0.53 \pm 0.35 \mathrm{~mm}$ preoperatively, $0.38 \pm 0.24 \mathrm{~mm}$ at 1 month postoperatively, and $0.41 \pm 0.18 \mathrm{~mm}$ at 3 months postoperatively. The differences in $\mathrm{TMH}$ among the three timepoints were statistically significant $(P<0.05)$ (Table 1, Fig. 1$)$.

The mean preoperative SIt value was $13.06 \pm 6.80 \mathrm{~mm}$, the 1-month postoperative SIt value was $14.11 \pm$ $5.41 \mathrm{~mm}$, and the 3-month postoperative SIt value was $15.72 \pm 4.51 \mathrm{~mm}$. The differences in SIt values among the three timepoints were statistically significant $(P<0.05)$ (Table 1, Fig. 2).

There were three types of changes within the 120 sets of TMH data: increased steadily (34/120 eyes), descended first and then ascended (32/120 eyes), and decreased steadily (54/120 eyes) (Fig. 2 ). Those with the increased steadily pattern were named group $A$, those with the descended first and then ascended pattern were named group $B$, and those with the decreased steadily pattern were named group C.

There were 34 cases in group $A$, and the mean age of the patients was $60.38 \pm 9.23$ years with a range from 39 to 76 years; 32 cases were in group $B$, with a mean age of $56.44 \pm 11.12$ years and a range form 33 to 78 years; finally, 54 cases were in group $C$, with a mean age of $55.85 \pm 11.48$ years and a range from 22 to 77 years. There was no significant difference in age among the three groups $(P=0.199)$, so age was comparable. The mean TMH in group A was $0.16 \pm 0.07 \mathrm{~mm}$ preoperatively, $0.30 \pm 0.10 \mathrm{~mm}$ at 1 month postoperatively, and $0.44 \pm 0.10 \mathrm{~mm} 3$ months postoperatively, the differences in $\mathrm{TMH}$ among the three 
timepoints were statistically significant $(P<0.05)$. The mean $\mathrm{TMH}$ in group $\mathrm{B}$ was $0.51 \pm 0.21 \mathrm{~mm}$ preoperatively, and $0.21 \pm 0.14 \mathrm{~mm}$ at 1 month postoperatively, and $0.48 \pm 0.24 \mathrm{~mm}$ at 3 months postoperatively. The differences in TMH among the three timepoints were statistically significant $(P<$ 0.05). The mean $\mathrm{TMH}$ in group $\mathrm{C}$ was $0.78 \pm 0.30 \mathrm{~mm}$ preoperatively, $0.52 \pm 0.26 \mathrm{~mm}$ at 1 month postoperatively, and $0.35 \pm 0.16 \mathrm{~mm}$ at 3 months postoperatively. The differences in TMH among the three timepoints were statistically significant $(P<0.05)$. The SIt values preoperatively, 1 month postoperatively and 3 months postoperatively among the three timepoints showed an increasing trend, and the differences were statistically significant $(P<0.05)$ (Table 1). Preoperatively, the TMH increased gradually from group $A$ to group $B$ to group $C(P<0.05)$. The differences in preoperative SIt values among the three groups were statistically significant, but there was only a difference and no gradual trend. The preoperative SIt length in group $\mathrm{C}$ was higher than that in group $\mathrm{A}$ and group $\mathrm{B}$ (Table 2).

There were 42 cases with an Slt $<10 \mathrm{~mm} / 5$ min preoperatively, and their mean age was $56.81 \pm 10.65$ years, with a range from 27 to 74 years; 78 cases had an SIt $\geq 10 \mathrm{~mm} / 5 \mathrm{~min}$ preoperatively, and their mean age was $57.38 \pm 11.05$ years, with a range from 32 to 78 years. There was no significant difference in age between the two groups $(P=0.094)$, so age was comparable. When the Slt $<10 \mathrm{~mm} / 5 \mathrm{~min}$ preoperatively, the SIt values were $5.57 \pm 3.28 \mathrm{~mm}$ preoperatively, $8.90 \pm 3.36 \mathrm{~mm}$ at 1 month postoperatively, and $12.79 \pm 3.41 \mathrm{~mm}$ at 3 months postoperatively. The results gradually decreased as the three times progressed, and the differences were statistically significant $(P<0.05)$. When the SIt was $\geq$ $10 \mathrm{~mm} / 5 \mathrm{~min}$ preoperatively, the SIt values were $17.09 \pm 4.33 \mathrm{~mm}$ preoperatively, $16.91 \pm 4.06 \mathrm{~mm}$ at 1 month postoperatively, and $17.29 \pm 4.24 \mathrm{~mm}$ at 3 months postoperatively. There were no significant differences among the three results $(P=0.245)$ (Table 3, Fig. 2).

The TMH was highly correlated with the SIt length preoperatively $(r=0.763, P=0.000)$, moderately correlated at 1 month postoperatively $(r=0.515, P=0.000)$, and not correlated at 3 months postoperatively ( $r=-0.097, P=0.292)$ (Fig. 3a, Fig. 3b, Fig. 3c). 
Table 1

Overall analysis results $(\mathrm{mm}$, mean $\pm S D)$

\begin{tabular}{|c|c|c|c|c|c|c|c|c|}
\hline Groups & & Eyes & Preoperative & $\begin{array}{l}1 \text { mo } \\
\text { postop. }\end{array}$ & $\begin{array}{l}3 \text { mo } \\
\text { postop. }\end{array}$ & $\begin{array}{l}F \\
\text { value }\end{array}$ & $\begin{array}{l}P \\
\text { value }\end{array}$ & $\begin{array}{l}P^{\prime} \\
\text { value }\end{array}$ \\
\hline \multirow{2}{*}{$\begin{array}{l}\text { Total } \\
\text { sample }\end{array}$} & $\mathrm{TMH}$ & \multirow[t]{2}{*}{120} & $0.53 \pm 0.35$ & $0.38 \pm 0.24$ & $0.41 \pm 0.18$ & 19.02 & 0.000 & 0.000 \\
\hline & SIt & & $13.06 \pm 6.80$ & $\begin{array}{l}14.11 \pm \\
5.41\end{array}$ & $\begin{array}{l}15.72 \pm \\
4.51\end{array}$ & 48.65 & 0.000 & 0.000 \\
\hline \multirow[t]{2}{*}{ Group A } & $\mathrm{TMH}$ & \multirow[t]{2}{*}{34} & $0.16 \pm 0.07$ & $0.30 \pm 0.09$ & $0.44 \pm 0.10$ & 217.99 & 0.000 & 0.000 \\
\hline & SIt & & $11.79 \pm 7.73$ & $\begin{array}{l}13.26 \pm \\
6.22\end{array}$ & $\begin{array}{l}15.15 \pm \\
4.69\end{array}$ & 20.37 & 0.000 & 0.000 \\
\hline \multirow[t]{2}{*}{ Group B } & $\mathrm{TMH}$ & \multirow[t]{2}{*}{32} & $0.51 \pm 0.21$ & $0.21 \pm 0.14$ & $0.48 \pm 0.24$ & 49.38 & 0.000 & 0.041 \\
\hline & SIt & & $11.13 \pm 5.41$ & $\begin{array}{l}12.37 \pm \\
3.98\end{array}$ & $\begin{array}{l}14.03 \pm \\
2.80\end{array}$ & 15.62 & 0.000 & 0.000 \\
\hline \multirow[t]{2}{*}{ Group C } & $\mathrm{TMH}$ & \multirow[t]{2}{*}{54} & $0.78 \pm 0.30$ & $0.52 \pm 0.26$ & $0.35 \pm 0.16$ & 113.83 & 0.000 & 0.000 \\
\hline & SIt & & $15.00 \pm 6.51$ & $\begin{array}{l}15.67 \pm \\
5.25\end{array}$ & $\begin{array}{l}17.07 \pm \\
4.85\end{array}$ & 14.19 & 0.000 & 0.000 \\
\hline
\end{tabular}

Table 2

Preoperative analysis results $(\mathrm{mm}$, mean $\pm S D$ )

\begin{tabular}{|llllll|}
\hline & Group A & Group B & Group C & Fvalue & Pvalue \\
\hline TMH & $0.16 \pm 0.07$ & $0.51 \pm 0.21$ & $0.78 \pm 0.30$ & 73.85 & 0.000 \\
\hline SIt & $11.79 \pm 7.73$ & $11.13 \pm 5.41$ & $15.00 \pm 6.51$ & 4.31 & 0.016 \\
\hline
\end{tabular}

Table 3

Independent analysis of the SIt lengths ( $\mathrm{mm}$, mean $\pm S D$ )

\begin{tabular}{|llllllll|}
\hline Groups & Eyes & Preoperative & 1 mo postop. & 3 mo postop. & Fvalue & $\boldsymbol{P}$ value & $\boldsymbol{P}^{\prime}$ value \\
\hline$<10 \mathrm{~mm}$ & 42 & $5.57 \pm 3.28$ & $8.90 \pm 3.36$ & $12.79 \pm 3.41$ & 657.65 & 0.000 & 0.000 \\
\hline$\geq 10 \mathrm{~mm}$ & 78 & $17.09 \pm 4.33$ & $16.91 \pm 4.06$ & $17.29 \pm 4.24$ & 1.42 & 0.245 & 0.000 \\
\hline
\end{tabular}

\section{Discussion}


To function, the tear system requires the joint participation of the tear secretion system and the drainage system, and they need to reach a certain state of balance. When one side changes and breaks the balance, the other side will also change in varying degrees $[8,9]$. The TMH can reflect the amount of tears stored in the conjunctival sac to some extent. When the tear secretion volume is too high and the drainage is insufficient, the tear storage is on the high side; conversely, when the tear secretion is insufficient and the drainage is suitable, the tear storage is low; finally, when the tear secretion is insufficient and the drainage is insufficient, the tear storage may be normal $[10,11,12]$. SIt is a typical quantitative method for determining the composition of tear fluid samples and can reflect the basic secretion of tears, and SIt is also a common detection index for patients with dry eyes $[13,14]$.

In patients with lacrimal duct obstruction, the function of tear drainage is basically "lost" $[15,16]$. When such patients undergo endoscopic dacryocystorhinostomy, it can be inferred that due to the "recovery" of drainage function, the TMH of these patients should all show a decreasing trend. However, the results of this study showed that the 120 sets of TMH data showed three trends; however, the overall trend gradually decreased, and the difference was statistically significant $(P<0.05)$. Each group of data was analysed independently and evaluate the individual the changes in trend. The statistical results show that only $45.00 \%$ (54/120 eyes) of the affected TMH showed a gradually decreasing trend; $28.33 \%(34 / 120$ eyes) of the affected TMH showed an upward trend; $26.67 \%$ (32/120 eyes) of the affected TMH decreased and then increased, which is "contradictory" with the original theoretical inference.

Since the tear drainage system is changed by EN-DCR, theoretically, SIt, as an indicator of the tear secretion system, should not be changed by the operation. However, the SIt data of 120 eyes in this study showed an increasing trend, and the difference was statistically significant $(P<0.05)$. As shown in Fig. 3 , when the preoperative SIt increased to a certain length, the SIt values showed a trend of "coincidence" preoperatively, 1 month postoperatively, and 3 months postoperatively. The preoperative SIt values were divided: "< $10 \mathrm{~mm} / 5 \mathrm{~min}$ " and " $\geq 10 \mathrm{~mm} / 5 \mathrm{~min}$. The results showed that when the preoperative SIt was < $10 \mathrm{~mm} / 5 \mathrm{~min}$, the results decreased gradually, and the difference was statistically significant $(P<0.05)$. However, there was no significant difference when the Sit was $\geq 10 \mathrm{~mm} / 5 \mathrm{~min}$ preoperatively $(P>0.05)$. Combined with the domestic and international research reports on the lacrimal system in recent years, the following analysis can be made.

Tears are absorbed by the lacrimal passage and transported to the surrounding cavernous body, which is innervated by the autonomic nerve and regulates tear drainage [17]. Under normal conditions, tears are continuously absorbed into the surrounding cavernous vessels. These blood vessels are connected to the blood vessels of the outer eye and can be used as a feedback signal for tear secretion. If tears are not absorbed, tear secretion will stop and dry eyes will occur $[3,18]$. The mechanism of implanting a lacrimal suppository or other methods of blocking the lacrimal passage in the treatment of xerophthalmia is to completely block the absorption of tears, resulting in the effect of "emptiness" in the lacrimal duct system. This effect is a strong stimulation signal produced by tears at the initial stage, but this stimulation effect weakens with time $[8,19]$. In normal individuals, there is an automatic balancing 
mechanism that can restore the secretion and drainage of tears to a equilibrium state in a certain period of time, but this mechanism is missing in some people [20].

At present, many studies have confirmed the value of $\mathrm{TMH}$ in the diagnosis of dry eyes, and this parameter can reflect the amount of tear secretion to some extent. Although there are some differences in the distribution range of TMH values among different populations, patients can be considered to have dry eyes when the TMH is less than $0.2 \mathrm{~mm}[21,22,23,24]$. In group $A$, the percentage of eyes with a TMH less than $0.2 \mathrm{~mm}$ was $61.76 \%(21 / 34)$ preoperatively, $17.65 \%(6 / 34)$ at 1 month postoperatively, and 0 at 3 months postoperatively (Fig. 4). After receiving EN-DCR, tears began to be absorbed and drained, feedback signals were sent out to stimulate tear secretion, and enhanced tear secretion relieved dry eyes to a certain extent.

In group B, the percentage of 32 eyes with a TMH less than $0.2 \mathrm{~mm}$ was $3.13 \%(1 / 32)$ preoperatively, $59.36 \%(19 / 32)$ at 1 month postoperatively, and $9.36 \%(3 / 32)$ at 3 months postoperatively (Fig. 4). In most eyes, the TMH was higher than $0.2 \mathrm{~mm}$ or even higher preoperatively and at 3 months postoperatively, so there was no sufficient evidence to indicate that most patients had severe dry eyes. However, more than half of the eyes had a TMH less than $0.2 \mathrm{~mm}$ at 1 month postoperatively, indicating that they had dry eyes. This can be explained by the fact that the affected eyes have partial of the function of tear secretion preoperatively, and after receiving EN-DCR, the absorption and drainage of tears gradually recover; however, the secretion function is not significantly enhanced at this time, so there is a trend that the height of the tear meniscus decreases for a short period of time. When the height of the tear meniscus decreases to a certain threshold, the automatic balancing mechanism is activated, the secretion function is gradually strengthened, and the equilibrium state is finally reached. Therefore, these patients show a changing trend of decreasing first and then increasing..

The change trend of 52 eyes in group $\mathrm{C}$ was consistent with the initial theoretical inference. The mean preoperative TMH was $0.78 \pm 0.30 \mathrm{~mm}$, and the minimum TMH was $0.26 \mathrm{~mm}$. At 3 months postoperatively, the minimum TMH was $0.06 \mathrm{~mm}$, and the proportion of eyes with a TMH less than $0.2 \mathrm{~mm}$ was $13.46 \%$ (7/52) (Fig. 4). The TMH and Slt values of the affected eyes were higher preoperatively. After receiving EN-DCR, tears are continuously absorbed and drained. It can be considered that because the $\mathrm{TMH}$ does not decrease to a certain threshold, there is no stimulus for the secretion of more tears. This can also be explained by the fact that the automatic balancing mechanisms of some affected eyes in group $\mathrm{C}$ are defective or deficient [25].

When the SIt was $<10 \mathrm{~mm} / 5$ min preoperatively, the tears were in a low secretion state [26, 27]. After ENDCR, under the stimulation of the successful absorption and drainage of tears, the tear secretion system "activated" the regulation mechanism, reversed the secretion of more tears, and gradually restored the normal secretion function. When the SIt was $\geq 10 \mathrm{~mm} / 5$ min preoperatively, the tear secretion function was basically normal, and even if the state of tear drainage changed, the tear secretion system still experienced no obvious changes. Therefore, it can be considered that the effect of EN-DCR on the tear secretion system is only shown in those with an abnormal tear secretion system. 
Many patients with an obstruction of the lacrimal duct but no symptoms of lacrimal discharge have been reported clinically. Some of these patients have dry eyes at the beginning and can still show no overflow of tears even if they have an obstruction of the lacrimal duct in the later stage; for others that have an obstruction of the lacrimal duct, the tears are not absorbed, the feedback signal is terminated, the secretion of tears is stopped, and finally there is no overflow of tears $[28,29]$.

In patients with an obstruction of the lacrimal duct, due to the "lack" of a lacrimal drainage system preoperatively, the $\mathrm{TMH}$ depends on the amount of tear secretion, and there is a high correlation between $\mathrm{TMH}$ and SIt length. When patients received EN-DCR, the lacrimal drainage system gradually recovered, and the correlation between TMH and SIt values gradually weakened. At 3 months postoperatively, there was almost no correlation between the two parameters. The reasons for the final lack of correlation between TMH and SIt values can be analysed as follows: the lacrimal secretion system and tear drainage system have basically returned to a balance, but there are great differences in tear secretion function and tear drainage function in this population, and the SIt values mainly depend on the tear secretion function, while the TMH is affected by both of functions; this makes the TMH and SIt values show no correlation at the last timepoint.

The automatic balancing mechanism and feedback regulation of the lacrimal system mostly depend on the cavernous structure of the lacrimal duct, which exists in the lacrimal sac and nasolacrimal duct. To make the lacrimal system function effectively and stably, the lacrimal drainage system needs to maintain a normal structure $[3,8]$. However, EN-DCR, as a diversion, impairs part of the function of the cavernous body of the nasolacrimal duct. Whether the loss of this part of the cavernous body will have a certain impact on the lacrimal system remains to be further studied and confirmed [30].

There are still some shortcomings in this study. (1) The number of cases is insufficient, and the results can be confirmed by a larger sample of patients in the future. (2) The follow-up time was insufficient, and the final measurement of TMH and the SIt values occurred at 3 months postoperatively, which could not reflect the long-term effect of EN-DCR on the lacrimal system. (3) The inconsistencies in patient eye habits postoperatively may have had a certain impact on the results of the study.

\section{Conclusions}

The results of this study show that EN-DCR has a certain impact on the lacrimal system in the short term. On the one hand, EN-DCR can drain tears stored in the conjunctival sac and relieve the symptoms of tear overflow; on the other hand, EN-DCR can also relieve dry eyes caused by insufficient lacrimal secretion. Therefore, the effect of EN-DCR is reflected not only in the tear drainage system but also in the tear secretion system and the interaction between the two systems; however its mechanism of influence and longer-term effects need to be proven by further research.

\section{Declarations}




\section{Availability of data and material}

The datasets used and/or analyzed during the current study available from the corresponding author on reasonable request.

\section{Abbreviations}

\section{EN-DCR}

Endoscopic dacryocystorhinostomy

$\mathrm{TMH}$

Tear meniscus height

SIt

Schirmer I test

SD

Standard deviation

\section{References}

1. Sousa TTS, Schellini SA, Meneghim RLFS, et al. Intra-Operative Mitomycin-C as Adjuvant Therapy in External and Endonasal Dacryocystorhinostomy: Systematic Review and Meta-Analysis. Ophthalmol Ther. 2020;9(2):305-19. doi:10.1007/s40123-020-00253-x.

2. Coumou AD, Genders SW, Smid TM, et al. Endoscopic dacryocystorhinostomy: long-term experience and outcomes. Acta Ophthalmol. 2017;95(1):74-8. DOl:10.1111/aos.13217.

3. Singh S, Ghosh A,Rath S. Imaging of proximal lacrimal system with time domain anterior segment optical coherence tomography in Asian Indian population. Orbit. 2017;36:251-5.

DOI:10.1080/01676830.2017.1337163.

4. Kaçaniku G, Ajazaj V, Shabani A, et al. Assessing the usefulness of different silicone tubes in external dacryocystorhinostomy. Med Arch. 2018;72(6):414-7. DOI:10.5455/medarh.2018.72.414-417.

5. Yuksel N,AkcayE, Ayan B,et al. Tear-Film Osmolarity Changes Following Dacryocystorhinostomy in Primary Acquired Nasolacrimal Duct Obstruction. Curr Eye Res. 2017;42:348-50. DOI:10.1080/02713683.2016.1196706.

6. Ishikawa S, Shoji T, Yamada N, et al. Efficacy of strip meniscometry for detecting lacrimal obstructive diseases among patients with epiphora. TransI Vis Sci Technol. 2019;8(6):8. DOI:10.1167/tvst.8.6.8.

7. $10.1097 /$ ICL. 0000000000000640

Ayyildiz T, Sezgin FM. The Effect of Ocular Demodex Colonization on Schirmer test and OSDI Scores in Newly Diagnosed Dry Eye Patients. Eye Contact Lens.2020;S39-S41. doi:10.1097/ICL.0000000000000640.

8. Kashkouli MB, Zolfaghari R, Es'haghi A, et al. Tear Film, Lacrimal Drainage System, and Eyelid Findings in Subjects With Anophthalmic Socket Discharge. Am J Ophthalmol. 2016;165:33-8. 
DOI:10.1016/j.ajo.2016.02.016.

9. Obi EE, Olurin O, Mota PM, et al. Assessment of lacrimal resistance using a manometric tear duct irrigation system. Orbit. 2018;37(4):273-9. DOI:10.1080/01676830.2017.1423082.

10. Wei S, Ren X, Wang Y, et al. Therapeutic Effect of Intense Pulsed Light (IPL) Combined with Meibomian Gland Expression (MGX) on Meibomian Gland Dysfunction (MGD). J Ophthalmol. 2020:1-7. DOI:10.1155/2020/3684963.

11. Tichenor AA, Ziemanski JF, Ngo W, et al. Tear Film and Meibomian Gland Characteristics in Adolescents. Cornea. 2019;38(12):1475-82. doi:10.1097/IC0.0000000000002154.

12. Baek JS, Jeong SH, Lee JH, et al. Cause and Management of Patients With Failed Endonasal Dacryocystorhinostomy. Clin Exp Otorhinolaryngol. 2017;10(1):85-90. doi:10.21053/ceo.2016.00192.

13. Tashbayev B, Utheim TP, Utheim $\varnothing A$, et al. Utility of Tear Osmolarity Measurement in Diagnosis of Dry Eye Disease. Sci Rep. 2020;10(1):5542. doi:10.1038/s41598-020-62583-x.

14. Fogagnolo P, Favuzza E, Marchina D, et al. New Therapeutic Strategy and Innovative Lubricating Ophthalmic Solution in Minimizing Dry Eye Disease Associated with Cataract Surgery: A Randomized, Prospective Study. Adv Ther. 2020;37(4):1664-74. doi:10.1007/s12325-020-01288-z.

15. Ali MJ, Paulsen F. Ultrastructure of the lacrimal drainage system in health and disease: A major review. Ann Anat. 2019;224(7):1-7. DOI:10.1016/j.aanat.2019.02.003.

16. Oh JR, Chang JH, Yoon JS, et al. Change in quality of life of patients undergoing silicone stent intubation for nasolacrimal duct stenosis combined with dry eye syndrome. $\mathrm{Br} \mathrm{J}$ Ophthalmol. 2015;99(11):1519-22. doi:10.1136/bjophthalmol-2014-306496.

17. Paulsen F. Anatomy and physiology of efferent tear ducts. Ophthalmologe. 2008;105(4):339-45. DOI:10.1007/s00347-008-1735-x.

18. Paulsen FP, Schaudig U, Thale AB. Drainage of tears: impact on the ocular surface and lacrimal system. Ocul Surf. 2003;1(4):180-91. DOI:10.1016/s1542-0124(12)70013-7.

19. Ali MJ, Paulsen F. Surfactant proteins: Role in lacrimal drainage disorders. Med Hypotheses. 2019;124(3):35-6. DOI:10.1016/j.mehy.2019.01.020.

20. Ali MJ, Rehorek SJ, Paulsen F. A major review on disorders of the animal lacrimal drainage systems: Evolutionary perspectives and comparisons with humans. Ann Anat. 2019;224(7):102-12. DOI:10.1016/j.aanat.2019.04.003.

21. Ge J, Liu N, Wang X, et al. Evaluation of the efficacy of optimal pulsed technology treatment in patients with cataract and Meibomian gland dysfunction in the perioperative period. BMC Ophthalmol. 2020;20(1):111. doi:10.1186/s12886-020-01357-5.

22. Liu S, Dong $\mathrm{H}$, Huang $\mathrm{XH}$, et al. Analysis of factors leading to lid wiper epitheliopathy. Eur Rev Med Pharmacol Sci. 2020;24(4):1593-601. doi:10.26355/eurrev_202002_20333.

23. Seol BR, Kang TG, Gu B. Intraocular pressure according to different types of tonometry (non-contact and Goldmann applanation) in patients with different degrees of bilateral tearing. PLoS One. 
2019;14(9):e0222652. DOI:10.1371/journal.pone.0222652.

24. Agnifili L, Brescia L, Scatena B, et al. Tear Meniscus Imaging by Anterior Segment-Optical Coherence Tomography in Medically Controlled Glaucoma. J Glaucoma. 2020;29(5):374-80. doi:10.1097/IJG.0000000000001469.

25. Lin H, Liu Y, He H, et al. Lacrimal Gland Repair after Short-term Obstruction of Excretory Duct in Rabbits. Sci Rep. 2017;7(1):82-90. doi:10.1038/s41598-017-08197-2.

26. Kang EY, Chen HT, Hsueh YJ, et al. Corneal Sensitivity and Tear Function in Recurrent Corneal Erosion Syndrome. Invest Ophthalmol Vis Sci. 2020;61(3):21. doi:10.1167/iovs.61.3.21.

27. Ozulken K, Aksoy Aydemir G, Tekin K, et al. Correlation of Non-invasive Tear Break-Up Time with Tear Osmolarity and Other Invasive Tear Function Tests. Semin Ophthalmol. 2020;35(1):78-85. doi:10.1080/08820538.2020.1730916.

28. Bladen JC, Cascone N, Pearson AR, et al. Dry eye after Lester Jones tube insertion for epiphora. Orbit. 2019;38(5):357-61. doi:10.1080/01676830.2018.1552710.

29. Xiang Q, Gao X, Fang J, et al. Lacrimal passage irrigation in children with Stevens-Johnson syndrome or toxic epidermal necrolysis: a five-year retrospective study. BMC Ophthalmol. 2019;19(1):22. DOI:10.1186/s12886-018-1014-9.

30. Paulsen FP, Thale AB, Maune $S$, et al. New insights into the pathophysiology of primary acquired dacryostenosis. Ophthalmology. 2001;108(12):2329-36. DOI:10.1016/s0161-6420(01)00946-0.

\section{Figures}

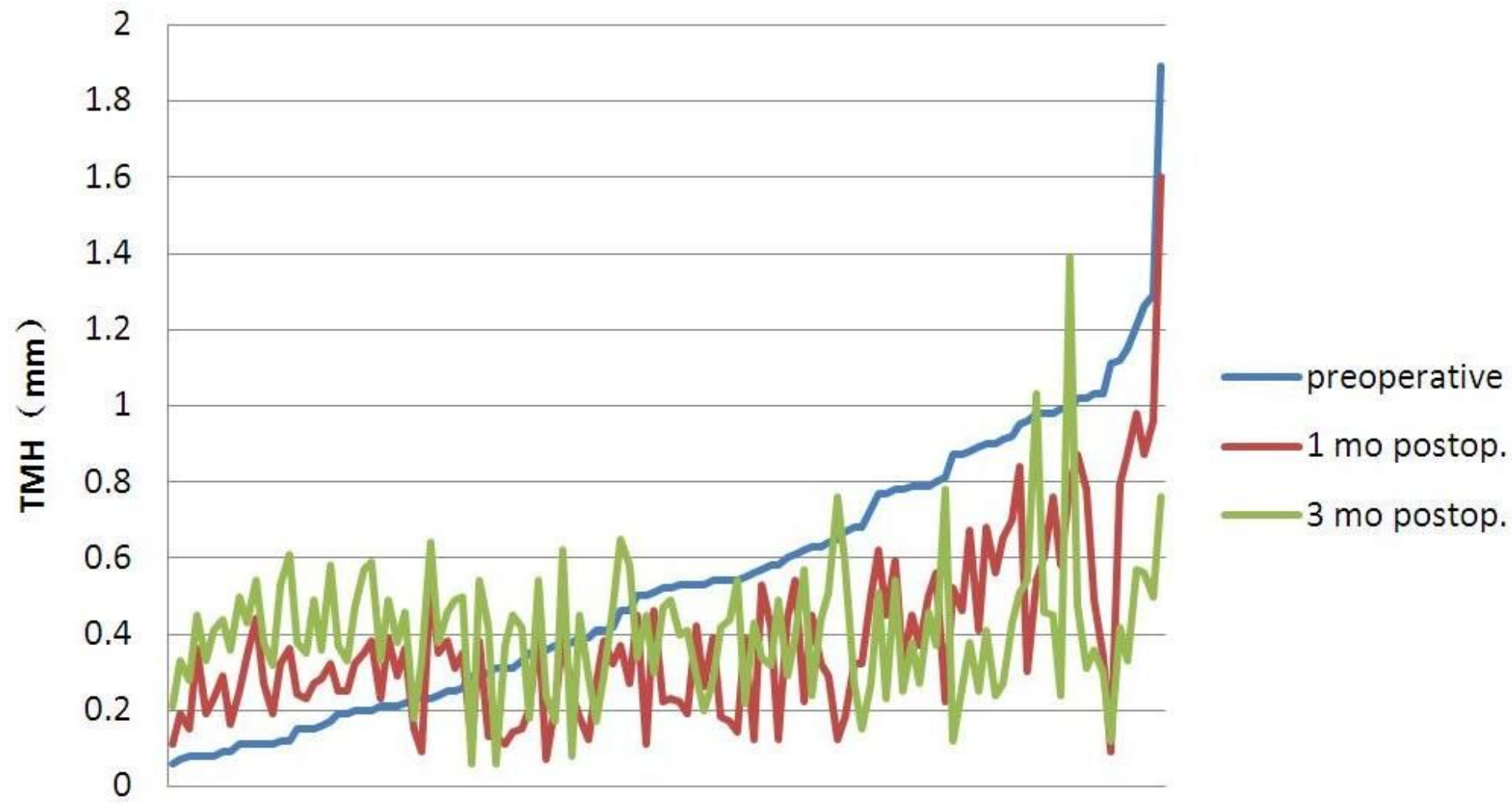


Figure 1

Overall TMH values Note: The horizontal axis is arranged according to preoperative TMH values from small to large

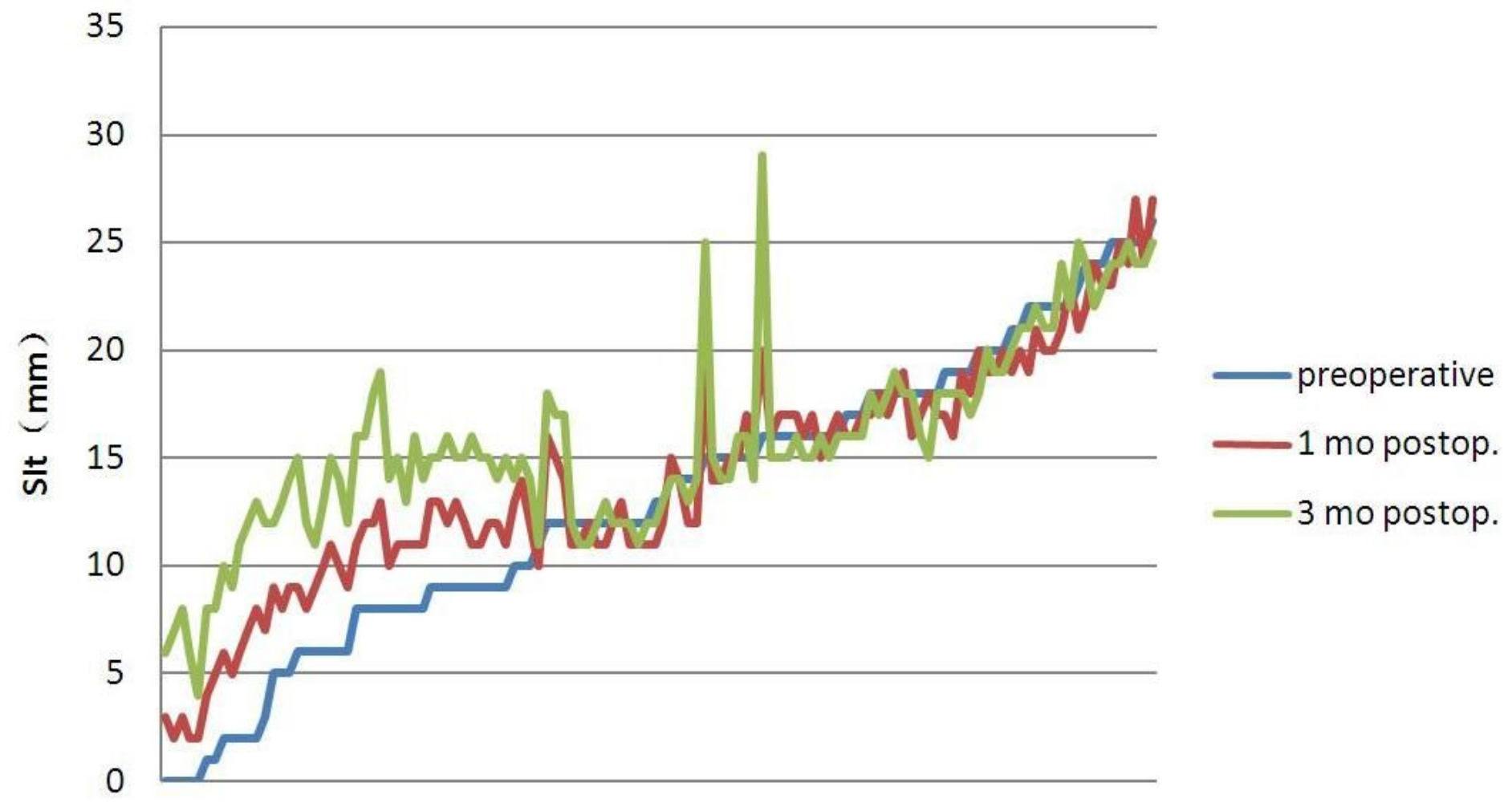

\section{Figure 2}

Overall SIt values Note: The horizontal axis is arranged according to the preoperative SIt values from small to large 

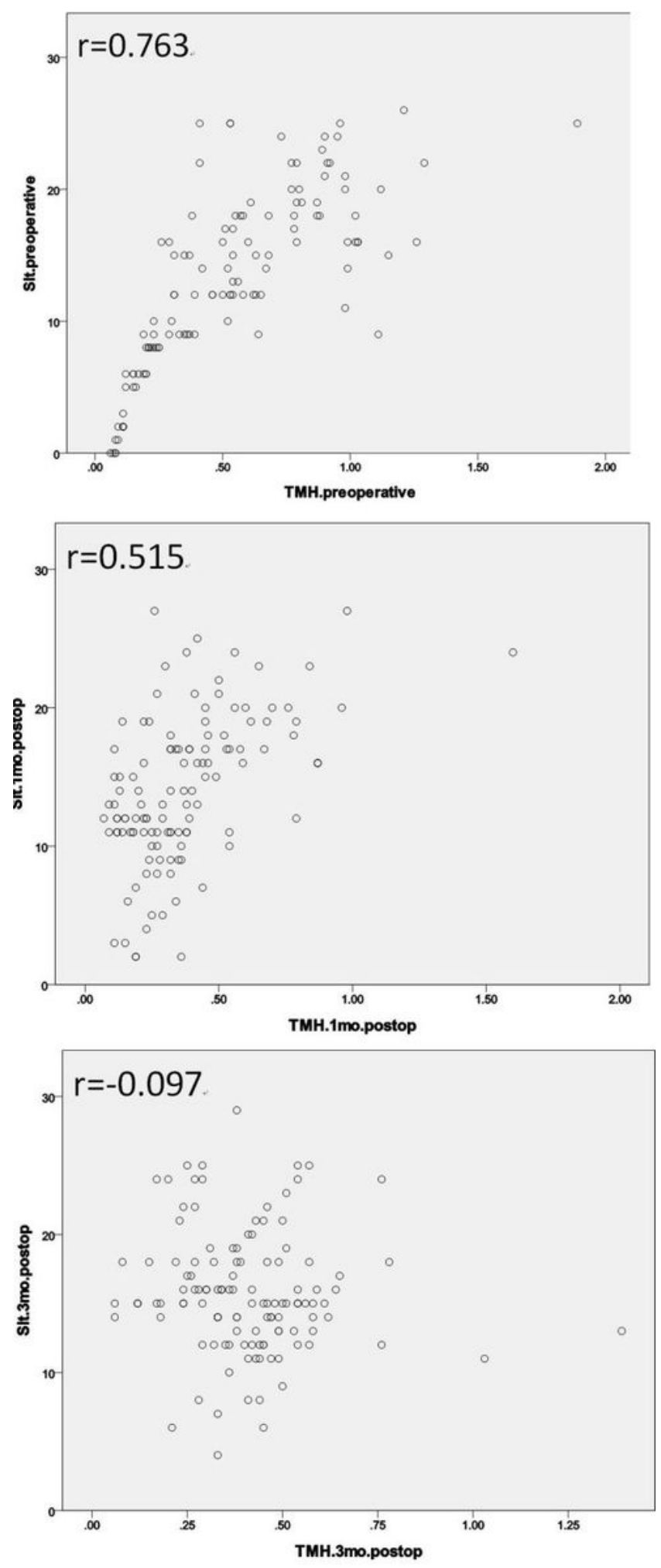

\section{Figure 3}

Scatter diagrams of the correlation between TMH and SIt values a: Preoperative; b: 1 month postoperative; c: 3 months postoperative 


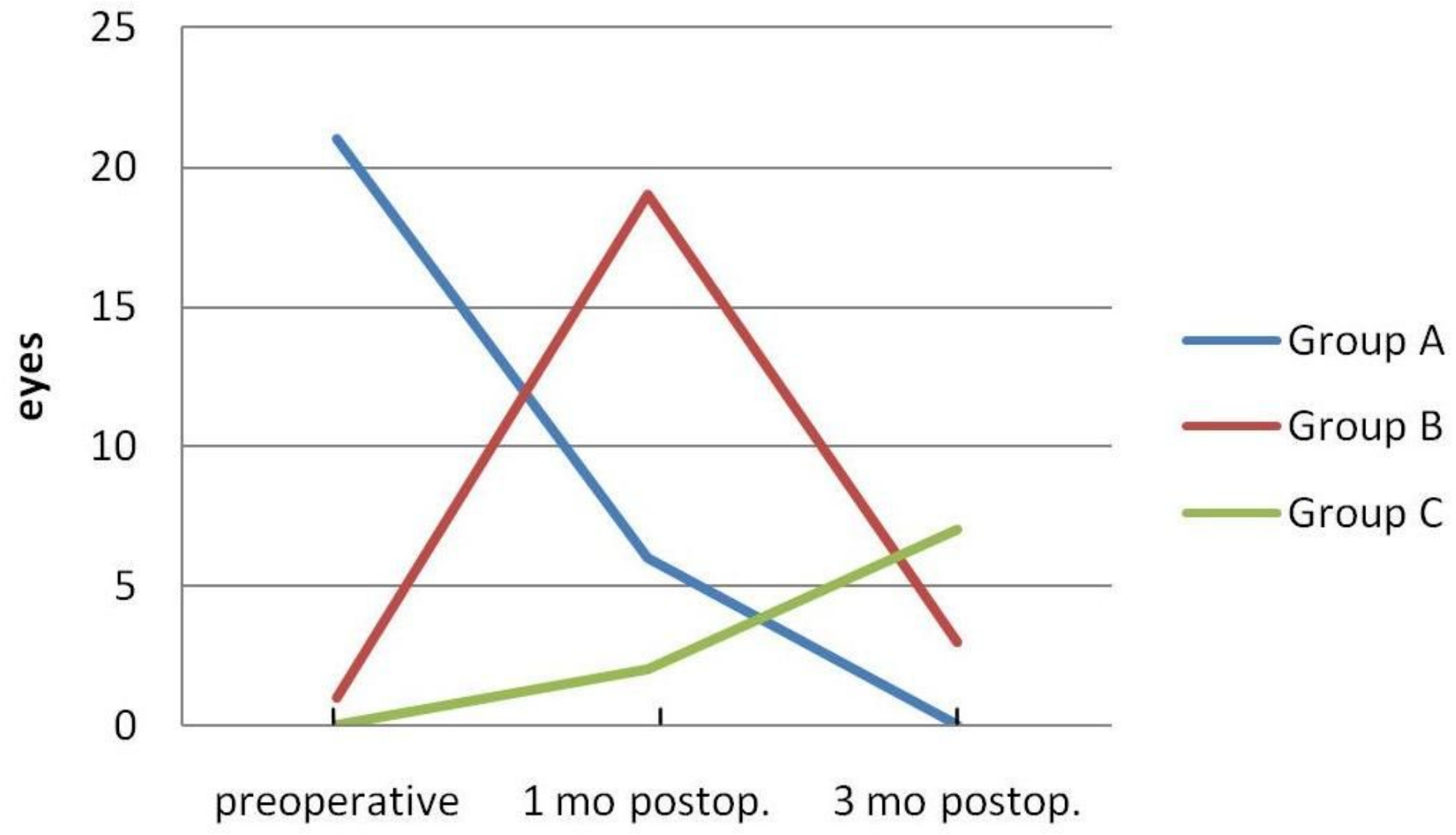

Figure 4

The number of eyes with a TMH less than $0.2 \mathrm{~mm}$ 